\title{
Dos encontros entre palhaças ou pistas para uma carto- grafia lúdica
}

\author{
ANDRÉA BENTES FLORES ${ }^{1}$ \\ WLADILENE LIMA²
}

\footnotetext{
Atriz e palhaça, docente da Escola de Teatro e Dança da Universidade Federal do Pará (ETDUFPA), nas disciplinas Pensar Histórico no Teatro, Estágio Il e Práticas de Inclusão com o Teatro. Mestre em Artes pelo Instituto de Ciências da Arte da UFPA (ICA/UFPA). Especialista em Estudos Contemporâneos do Corpo: Criação, Difusão e Recepção, vinculada ao ICA/UFPA. flores_terapeuta@yahoo.com.br

2 É professora na Universidade Federal do Párá, no curso técnico de formação de ator, na graduação em dança e em teatro, na especialização em Estudos Contemporâneos do Corpo e nos mestrados, acadêmico e profissional, em Arte do PPGArtes Universidade Federal do Pará. Possui Pós-doutoramento em Estudos Culturais junto a Universidade de Aveiro. Mestrado e doutorado em Artes Cênicas pelo Programa de Pós-graduação em Artes Cênicas da Universidade Federal da Bahia PPGAC/UFBA e graduação em Ciências Sociais pela UNAMA. gordawlad@yahoo.com.br
} 


\section{- RESUMO}

Este artigo atravessa algumas pistas para a constituição de uma cartografia lúdica, perpassada pelo mergulho na sinceridade da autora em sua experiência de mulher palhaça amazônida, desejosa de estabelecer encontros e transcriá-los ou transvê-los em um processo criativo, que é também pesquisa. Para tanto, segue em busca dos caminhos que a levam aos encontros, a partir do conceito de ritornelo deleuziano, desvelando o delineamento de um olhar, atravessado por memórias da infância, trechos poéticos e recortes de conceitos, a partir dos quais reconhece a relevância da mulher cômica e do território amazônida onde a autora está situada, enquanto constituintes de um mapa, construído em jogo, ora correspondente à própria pesquisa, ora ao processo criativo em que deve resultar. Entre potências pessoais de seu feminino amazônida, a autora revela o processo de entranhar-se no objeto de pesquisa e criação, assumindo-o em jogo para sua cartografia.

\section{PALAVRAS-CHAVE}

Palhaça, cartografia, jogo.

\section{- ABSTRACT}

This article runs through some clues to compose a playful cartography, wrought by the dip in the author's sincerity, on her experience as Amazonian clown woman, willing to set up meetings and transcriate them in a creative process, which is research also. Therefore, the author follows in search of paths that lead to encounters, throw the deleuzian concept of refrain, unveiling the design of a look, crossed by childhood memories, poetic excerpts and concepts clippings, from which she recognizes the importance of the clown woman and the Amazonian territory, where her performance is located, as constituents of a map, built in game, sometimes corresponding to the research itself, sometimes to the creative process that it might result. Among her personal Amazonian female potency, the author reveals the process of becoming ingrained on the object of research and creation, assuming it on a game, for her cartography.

\section{- KEYWORDS}

Clown women, cartography, play.

Agora, enfim, entreabrimos o círculo, nós o abrimos, deixamos alguém entrar, chamamos alguém, ou então nós mesmos vamos para fora, nos lançamos. [...] E dessa vez é para ir ao encontro de forças do futuro, forças cósmicas. Lançamo-nos, arriscamos uma improvisação. Mas improvisar é ir ao encontro do Mundo, ou confundir-se com ele. Saímos de casa no fio de uma cançãozinha. Nas linhas motoras, gestuais, sonoras que marcam o percurso costumeiro de uma criança, enxertam-se ou se põem a germinar "linhas de errância", com volteios, nós, velocidades, movimentos, gestos e sonoridades diferentes (DELEUZE; GUATTARI, 1997, p. 101-102).

Meu ponto de partida para esta escrita é a solidão. Um estado solitário real, que faz parte de minha condição como artista e que me serviu, por algum tempo, como proteção do caos. Hoje, no entanto, lanço-me arriscadamente em uma tentativa de encontrar-me com outros, na verdade, com outras. Mulheres palhaças amazônidas, como eu. Compartilho, aqui, algumas implicações decorrentes da necessidade de estar junto, entre pessoalidades e amadurecimentos em pesquisa, que iniciam na solidão e aportam em um processo criativo em devir.

Sou uma palhaça sem grupo. Atuar sozinha não foi uma escolha pessoal; as 
circunstâncias levaram-me a resistir desta forma. Logo após atuar junto aos Palhaços Trovadores ${ }^{3}$ em mais um de seus espetáculos - O Mão de Vaca, inspirado na obra de Moliére, passei por momentos difíceis, sem rumo em meu percurso artístico. Àquela altura, eu acreditava que ser palhaça significava estar misturada a outros palhaços, ser como eles, de preferência junto àquele grupo, com quem estive por perto durante três anos até ali, como atriz convidada. Havia também a "Trupe das Meias Trocadas", grupo no qual engatinhava um trabalho, junto a outras duas palhaças. Ao final daquela temporada, no entanto, os convites ficaram escassos e, ao mesmo tempo, eu havia me graduado na universidade. Desempregada por seis meses, tentando - sem sucesso - viver somente de teatro, recebi uma proposta de trabalho no interior do Pará. Fui embora. Lá fiquei por cinco meses, atuando somente como terapeuta ocupacional, sem teatro e pouco feliz. Certa de que faltava algo, tentava manter-me firme naquele lugar.

Era como se, voltando a uma atitude comum em minha infância, buscasse pelo meu travesseiro, comprimindo-o em um forte abraço, para sentir-me protegida dos perigos noturnos e poder circular pelo terrível corredor que conduzia à cozinha de minha casa. O travesseiro era como uma arma de guerra, que almejava empunhar naquela difícil situação em que me encontrava. Algo próximo à atitude da criança que cantarola para tranquilizar-se, com medo, no escuro, imagem de que Deleuze e Guattari (1997) lançam mão para identificar um primeiro aspecto do ritornelo ${ }^{4}$. A instauração de um começo de ordem, pontual, quando diante do caos assustador.

Seria aquela falta referente a outros palhaços? Talvez sim, em parte. A maior parcela, no entanto, era falta de mim. Um outro eu, tão ou mais forte que a terapeuta trabalhando por vezes mais de oito horas por dia. Essa outra gritava todas as noites em sonhos, devaneios, sob a forma de "Bilazinha da Mamãe", minha palhaça. Voltei de mala e cuia, em busca de ser palhaça, com a certeza de que qualquer nova tentativa de deixá-la seria perder-me.

Não encontrei, entretanto, portas abertas. Parecia uma punição da vida. Só eu sabia a dor que carregara em outra cidade, até descobrir meu caminho. Estava voltando para finalmente abraçá-lo e dei de encontro com duas duras realidades: os Trovadores seguiam seu próprio caminho, do qual eu não fazia parte; ao mesmo tempo, a "Trupe das Meias Trocadas" se esvaía em desencontros. Pensei que talvez houvesse me enganado.

Lembrei, porém, dos gritos dentro de mim, ajudada pelas reflexões sobre minha atuação na rua, que empreendia àquele tempo, registrada em Flores (2011). Constatei, então, que havia voltado em busca de mim, não de outros. O objetivo que almejava alcançar era diferente. Ser palhaça significava encontrar-se comigo. E que dura jornada solitária!

Foi preciso muito esforço para continuar. Acreditar que eu sou palhaça em qualquer lugar e de qualquer modo, mesmo ridiculamente solitária e sem reconhecimento. Descobri na solidão um presente. "A força de um artista vem das suas derrotas. Só

3 O grupo "Palhaços Trovadores" é pioneiro em fazer teatro com palhaços na cidade de Belém e completou 14 anos em 2012. É composto por 14 integrantes, sendo 8 mulheres.

4 Cf. Antônio HOUAISS; Mauro de Salles VILLAR. Dicionário Houaiss da Língua Portuguesa, p. 2463: "ritornelo s.m. (sXVIII cf. NascOp) 1 HIST.MÚS refrão, frase repetida em cantos ou versos, como nos madrigais italianos dos sXIV e XV [...]". Neste texto, no entanto, abordo o ritornelo enquanto conceito inventado na filosofia de Deleuze e Guattari. 
a alma atormentada pode trazer para a voz um formato de pássaro", já dizia o poeta Manoel de Barros (1996). Condição amarga, mas um prato cheio para voar e descobrir minha condição precária, sem talento, sem ninguém, desolada, risível: minha condição de palhaça. Uma dor forte de humana, da qual aprendi a rir, enquanto também aprendia a reconhecer-me palhaça, gênero feminino, atuante em um território específico, a Amazônia.

Independente de gênero, ser palhaço significa estar em estado de sinceridade, de exposição do ridículo de cada um, singularidades muitas vezes ocultas pelas exigências sociais. "O clown não existe fora do ator que o interpreta. Somos todos clowns. Achamos que somos belos, inteligentes e fortes, mas temos nossas fraquezas, nosso derrisório, que, quando se expressa, faz rir" (LECOQ, 2003, p. 213).

Palhaças e palhaços são perdedores, por permitir ao público entrar em contato com nossa natureza humana, frágil e transitória, que insistimos por escamotear, julgando-nos superiores. É premissa do estado de palhaço a abertura ao outro, deixando-se ver em suas bobagens, tolices, derrisórios, algo que se busca ao longo do processo de descoberta do seu próprio palhaço (ou clown pessoal 5 ).

Restava-me, portanto, aproveitar minha derrisória solidão e nela mergulhar. Agora, o travesseiro não servia mais. Era necessário armar a "cabana", buscando novamente uma imagem da infância: alguns lençóis amarrados entre si, com partes presas à maçaneta da porta e ao espelho da cama, formando um espaço interior que eu habitava para proteger-me dos perigos e, assim, poder brincar em paz com as bonecas que carregava para dentro. Movimento semelhante ao segundo aspecto do ritornelo deleuziano, na imagem da construção da casa, com fins de proteger o espaço interior dos rebuliços externos. "Eis que as forças do caos são mantidas no exterior tanto quanto possível, e o espaço interior protege as forças germinativas de uma tarefa a ser cumprida, de uma obra a ser feita" (DELEUZE; GUATTARI, 1997, p. 101). Aqui, a necessidade é organizar um espaço delimitado, onde as forças íntimas terrestres não sejam submersas, mas resistam, emprestando, inclusive, um pouco do caos. Olhar para mim, delimitar-me, aprender com a experiência, brincar, para não sucumbir.

Tem sido assim. Aprendo a rir de minha condição no mundo, descobrindo minúcias sobre Bilazinha, ao modular sua voz, incomodar-me com sua roupa etc., sem nunca abandonar a cena. Agora, no entanto, a palhaça e a palhaça-atriz exasperam a necessidade do outro, necessidade esta que, na verdade, nunca deixou de existir e foi a grande responsável pela minha sensação de precariedade. Como uma expiração após longa inspiração, jogo o ar para fora e vou em busca de referências, encontros, corpo a corpo, vozes, histórias cruzadas. Levanto o lençol da cabana, abro a porta da casa, identificando o terceiro aspecto do ritornelo. A companhia das bonecas não é mais suficiente. A solidão já não dá conta do que ocorre comigo. Preciso estar junto a outras humanas e sei exatamente quem são: palhaças amazônidas, como eu.

O ritornelo tem os três aspectos, e os torna simultâneos ou os mistura: ora, ora, ora.

5 O termo clown pessoal foi criado por Jacques Lecoq (2003), designando a persona palhaço(a) que cada um descobre, a partir de técnicas específicas, a partir de suas próprias singularidades. Por isso, não se cria uma palhaça; descobre-se a palhaça que está dentro de si. 
Ora o caos é um imenso buraco negro, e nos esforçamos para fixar nele um ponto frágil como centro. Ora organizamos em torno do ponto uma "pose" (mais do que uma forma) calma e estável: o buraco negro tornou-se um em-casa. Ora enxertamos uma escapada nessa pose, para fora do buraco negro. [...] Enfim, o ponto se atira e sai de si mesmo, sob a ação de forças centrífugas errantes que se desenrolam até a esfera do cosmo (DELEUZE; GUATTARI, 1997, p. 102).

Os três aspectos do ritornelo ocorrem ao mesmo tempo, sem evolução ou sequência. Semelhantemente, os relatos que compartilhei continuam a misturar-se nesta necessidade atual. Também o desejo de "sair de mim mesma" e ir ao encontro do outro sempre me acompanhou, como já disse anteriormente. Na verdade, nunca estive inteiramente só. Teatro é uma arte coletiva. Mesmo assim, a solidão, em ritornelo faz parte de minha trajetória artística e de pesquisa.

Quando identifico o ritornelo desta pesquisa, passo a buscar como dar conta de suas intensidades. Em outras palavras, o que significa esse meu movimento de improvisar ir até o outro? Aqui, tateio alguns sentidos de resposta, enquanto desvelo pistas de uma cartografia lúdica que brinca com meu corpo de mulher palhaça e pesquisadora.

Inicio tentando compreender com que olhar parto para encontrar nuances do feminino cômico amazônida. Reflito se é relevante realçar essa especificidade de gênero da palhaça, questionar se existe, de fato, para não resultar em perda de tempo, antes de lançar-me em devaneios de pesquisa nesse universo.

Para mim, existe; e sua relevência está no estado de sinceridade clownesco. Luis Otávio Burnier (2009, p. 218), pesquisador do Lume ${ }^{6}$, uma das principais referências brasileiras para o treinamento do palhaço, ressalta o quanto, desde o processo iniciático, a autenticidade do palhaço é que resultará na comicidade desejada:

\begin{abstract}
O processo de descoberta do clown pessoal provoca a quebra de couraças que usamos na vida cotidiana. [...] Mais do que formas estereotipadas, o que causa o riso são as manifestações autênticas advindas da sensação de desconforto e insegurança do clown diante do público [...] A criação do clown, ao longo dos diversos exercícios, significa entrar em contato com esses aspectos humanos e sensíveis do ator e sua decorrente corporificação. Ou seja, o clown será construído com o que haverá de corpóreo, com as ações físicas que surgirem nesse processo iniciático, ou, mais precisamente, com as corporeidades que alimentam as ações físicas.
\end{abstract}

Tanto o clown, quanto a clown ${ }^{7}$ são resultado de pessoalidades corporificadas, expostas ao riso. Percebo que, neste sentido, cabe falar em nuances próprias do feminino para a comicidade. Se mulheres e homens não são iguais, uma palhaça desenvolve-se com base no feminino, papel socialmente imbricado em significados singulares, que não podem ser tratados como idênticos ao masculino. A tradição do palhaço, entretanto, conforme já denunciado por outras pesquisadoras (CASTRO, 2005; CASTRO, 2010; MENEZES, 2011), sempre esteve fortemente ligada ao ho-

\footnotetext{
6 Cf. www.lumeteatro.com.br

7 Defendo que construções linguísticas como "a palhaça" e "a clown" ou "a mulher clown" são possíveis, mesmo que o termo clown seja usado na literatura somente no masculino, até então. Trata-se de uma postura política, de afirmação do feminino nessa arte.
} 
mem, através de registros históricos silenciosos sobre a mulher cômica, de gags ${ }^{8}$ construídos a partir da experiência do masculino e de uma série de sistemas que necessitam ser reformulados, mediante a vivência do feminino.

Não compreendo que precise traçar uma diferença entre palhaços e palhaças. Apoio-me em Deleuze (2006) para compreender que a perspectiva necessária está na repetição. Diferença não significa oposição e está muitas vezes atrelada a representações, a simulacros, máscaras. Repetir, por sua vez, não significa generalizar, refazer o igual, mas comportar-se em relação a algo único e singular. Não significa tentar compor uma segunda e uma terceira vez à primeira, mas elevar a primeira à enésima potência.

Para a palhaça, não servem os simulacros, o papel cotidianamente desempenhado. Importa, isto sim, a natureza humana, os ridículos de nossa condição. Potência feminina na comicidade, repetição do mesmo, da figura cômica, mas na potência de ser mulher. Trata-se de reconhecer que mulheres têm sua própria experiência de vida no mundo, seus ridículos, seu cômico, determinado não pelas diferenças de sexo, mas pela riqueza de vivências próprias, social, histórica e culturalmente construídas.

Aqui resolvo brincar com alguns conceitos que encontro pelo caminho, tornando-os parte do mapa que desenho em torno da comicidade feminina. Encontro-me com os princípios de Klauss Vianna, observando-o pela lente de Jussara Miller (2007), para refletir sobre caminhos possíveis para que a mulher encontre esses registros em sua corporificação da palhaça. O que a autora chama de técnica Klauss Vianna tem como um de seus pressupostos a busca por um corpo presentificado em suas sensações, através do qual o atuante é também seu espectador; este, reconhecido em seu caráter singular. Minha busca reverbera aqui, quando encontro aproximações metodológicas para buscar esse corpo cômico, feminino, resultante de um processo de mergulho em nós mesmas, descoberta de singularidades potenciais resultantes da experiência vivida como mulher.

Como desdobramento dessas aproximações, empresto, ainda, o termo dança como vida, que resulta do contato com camadas interiores de si, o acesso ao corpo presentificado de Klauss Vianna (MILLER, 2007). Para meus objetivos nesta pesquisa, utilizo-o para falar de uma dança pessoal do cômico feminino. Dançar é, aqui, a ação de um corpo consciente de suas funções, limitações e possibilidades, resultantes da experiência dos sujeitos no mundo, que se movimentam conforme sua própria história. Como uma mulher, que se lança em comicidade compreendendo-se no feminino e atua inevitavelmente interligada à vivência sócio-histórica dessa condição.

Lembro-me do termo dança pessoal também entre os escritos do Lume. Nesse contexto, ela resulta de um treinamento energético, voltado para quebrar estereótipos e levar o atuante, não somente a palhaça, a um contato mais autêntico com sua humanidade, uma ligação profunda consigo mesmo. Burnier (2009, p.139-140) afirma que "esse tipo de treinamento permite que cada ação tenha uma íntima relação com a pessoa e seu universo interior. Ele busca atingir energias interiores mais profundas que estão normalmente em estado potencial no indivíduo". No caso a que me refiro, penso na dança pessoal como um processo para atingir potências do cômico feminino.

8 Gags são acidentes cômicos, sempre presentes nas ações de palhaços em cena. 
Algo semelhante, também, aos pressupostos para o teatro do polonês Jerzy Grotowski (2010), que, inclusive, influenciam significativamente o trabalho do Lume. Guardados os propósitos e dimensões específicas do trabalho desse mestre do teatro, afirmo que seu método ressoa na dança pessoal do cômico feminino de que trato aqui, quando propõe que a construção cênica seja, para o atuante, um processo de desvelar a si mesmo. Em uma total doação de si mesmo, eliminam-se bloqueios e alcança-se verdade no fazer, algo intimamente relacionado a um autêntico desnudar do artista. Como a palhaça, em suas verdades cômicas, resultantes do encontro com potências de um feminino singular.

Acredito que haja vários femininos, por isso concebo que esse mergulho em si resulta em potências singulares. Ora, o que é o feminino? Cada vivência é única, de maneira que a busca da palhaça é pela ativação de um arcabouço potencial próprio, eu- cômica. Formas estereotipadas e generalizantes do que é ser mulher não cabem aqui. Na verdade, penso que a real necessidade é por desconstruções das formas cotidianamente incutidas como aceitáveis para uma mulher.

Russo (2000) aponta algumas pistas neste sentido, propondo uma estreita associação entre o feminino e o grotesco, como forte e representativa afirmação cultural e de gênero. Trata-se de uma relação bem próxima, a meu ver, do estado de palhaça, imbricada em ridículos, derrisórios, grotescos.

A dança pessoal do cômico feminino, dança da vida, refere-se, neste sentido, ao corpo da palhaça que age consciente de suas potências e torna-se motivo de riso, grotesca, a partir de referenciais que encontra em si mesma, em sua experiência no mundo. O encontro com o corpo próprio desenvolve, assim, uma comicidade que parte da vivência sócio-histórica e cultural de ser mulher, expondo o ridículo desta condição.

Minha vivência de palhaça está arraigada na cidade de Belém, Pará. Este pequeno espaço situado na Amazônia9 . Na verdade, Amazônias, plurais, diversas, como quer Gonçalves (2012), exprimindo as complexas realidades sociais, históricas e culturais que marcam este território. Bilazinha da Mamãe resulta de minha experiência rizomática neste meio de muitas Amazônias, a qual atravessa minha dança pessoal de mulher cômica.

Descubro, em ritornelo, que não quero e não posso dançar sozinha, como compartilhei anteriormente. Uma vez que experimentar o outro é uma necessidade latente, sou impelida a reconhecer-me inserida em um meio maior, onde habitam repertórios, histórias de vida, cores, olhos, narizes de palhaça, asfalto, rios, florestas. Estou em multiplicidades poéticas. Estou viva.

O vivo tem um meio exterior que remete aos materiais; um meio interior que remete aos elementos componentes e substâncias compostas; um meio intermediário que remete às membranas e limites; um meio anexado que remete às fontes de energia e às percepções-ações. [...] A transcodificação ou transdução é a maneira pela qual um meio serve de base para um outro ou, ao contrário, se estabelece sobre um outro, se dissipa ou se constitui no outro (DELEUZE; GUATTARI, 1997, p. 103).

\footnotetext{
9 Neste artigo, toda vez que me referir à Amazônia, estou circunscrita à área territorial da região geopolítica, delimitada entre os Estados do Amazonas, Acre, Roraima, Rondônia, Pará, Amapá, Tocantins (com exceção do extremo sul), além de trechos do Mato Grosso e do Maranhão. Cf. www.ibge.com.br .
} 
Meu movimento de improviso até o outro significa submeter-me à transdução, processo pelo qual deixo os meios que compõem meu viver-palhaça atravessarem-se, dissiparem-se, constituírem-se um no outro. Transdução ou transcriação de tudo o que passa pelas membranas entre nós, pelo meu espaço interno de vivência de mulher palhaça, pelo exterior de histórias de vida e repertórios de outras cômicas amazônidas e pelas Amazônias onde habitamos em espaços-tempos heterogêneos.

Falo em transcriação livremente, unindo o termo deleuziano citado, transcodificação ou transdução, à palavra criação, própria do fazer artístico. A transcriação, entretanto, é um termo criado por Haroldo de Campos (2011), em seus escritos reflexivos a respeito de seu trabalho como tradutor de poesias. Constitui-se em uma crítica à mera tradução do texto poético, compreendendo que termina por esvaziá-lo, ao tornar crível uma forma ideal de trazê-lo ao entendimento de outra língua e cultura. Transcriar seria o resultado de conceber a poesia como um horizonte móvel, modelável. Neste sentido, passa-se do irrepetível ao disponível a formas artísticas ${ }^{10}$.

Manoel de Barros (1996, p. 75) utiliza outro termo semelhante, em um de seus poemas, "As lições de R.Q.". Afirma o poeta: "Arte não tem pensa: o olho vê, a lembrança revê, e a imaginação transvê. É preciso transver o mundo. Isto seja: Deus deu a forma. Os artistas desformam". Passo a compreender, a partir daí, que a criação tende a conferir outra forma para a realidade de onde se origina e resolvo adotar o verbo transver nesta minha cartografia.

Por essa perspectiva, transver designa meu movimento de ir ao encontro das palhaças e, ao compartilhar essa experiência, recriar suas intensidades em um espetáculo - desejo que tenho como resultado a ser gerado. Transcriar, em meu corpo-em-vida, esse entre-dois em que me situo. A corporificação dos encontros leva-me a um processo criativo em devir, onde deixo a solidão, contudo sem abandoná-la. Como um monólogo polifônico, em que um enorme grupo de palhaças amazônidas esteja comigo e eu finalmente faça parte de um grupo.

O pensamento e a sensibilidade têm acesso a uma nova dimensão na qual cada gota de suor, cada flexão muscular, cada arfar, se tornam em outros tantos símbolos duma história cujo movimento próprio é reproduzido pelo meu corpo enquanto o meu pensamento abrange o seu significado. Sinto-me envolto numa inteligibilidade mais densa no seio da qual os séculos e os lugares se interpenetram e falam linguagens finalmente reconciliadas (LÉVI-STRAUSS, 1996, p. 51).

Abro um pequeno parêntese, momento em que empresto uma imagem proposta pelo antropólogo Lévi-Strauss, semelhante a que se delineará nesse processo criativo, embora nada tenha a ver com a criação cênica em sua escrita original. Substituo apenas o termo "reproduzido pelo meu corpo" por "transcriado pelo meu corpo". Vou em busca do suor, da flexão muscular, de símbolos que deem conta do interpenetrar de lugares, do levantar do lençol da cabana. Quero ativar um potencial arcabouço criativo em diálogo com outras mulheres palhaças amazônidas.

No processo de corporificar cada percepção-ação e interpenetrar os meios, compo-

\footnotetext{
${ }_{10}$ A transcriação já é utilizada também em escritos sobre o teatro, no sentido da liberdade com que o atuante cria a cena a partir da transformação de um texto dramatúrgico ou literário, ou mesmo de outros elementos sígnicos. Cf Linei HIRSCH. Transcriação teatral: da narrativa literária ao palco.
} 
nho um mapa-espetáculo. Confesso que esse desafio provoca-me ansiedade, medo e excitação. É, ao mesmo tempo, pavoroso e instigante. Tamanha exposição de mim mesma parece levar-me a perder meus contornos, minha individualidade, lançando-me toda ao outro. Os contornos, porém, já não me eram suficientes; havia mesmo a necessidade de dissolvê-los, variar, estabelecer encontros, encontrar alegrias.

\begin{abstract}
A variação contínua, isto é, a variação da nossa força de existir ou da nossa potência de agir, é variação da própria trajetória da vida. E a trajetória não é homogênea. Quer dizer que o estofo da variação contínua é feito de encontros, de encontros mil, com o alimento, com os ares saudáveis, com a poluição, com entes amáveis e odiáveis etc. Em função de encontros extensivos e intensivos, encontros que se misturam nessa variação contínua, é que Deleuze vê o aparecimento de uma 'pequena alegria' (ORLANDI, 2010).
\end{abstract}

Se, a princípio, acreditava que meu interesse estava simplesmente em conhecer nuances da comicidade feminina amazônida, reconheço que a pesquisa ganhou outra proporção quando resolvi desnudar-me e assumir meu desejo de construção de um espetáculo, ainda que isto seja assustador. Nesse momento, encontro sinceridade para a pesquisa, como se acionasse um princípio da palhaçaria, o mesmo pelo qual descobri haver relevância em tratar sobre mulheres palhaças: a verdade da cômica, arraigada em suas vivências.

Ao assumir que não me basta somente contar histórias e identificar repertórios de comicidade feminina na Amazônia, mas necessito experimentá-las no corpo, encontro anseio semelhante ao de Julia Varley, com a escrita de seu livro Pedras d'água: bloco de notas de uma atriz do Odin Teatret. Trata-se de transmitir algo e também descobrir como fazer. Nesse processo, reconheço que as realidades pesquisadas serão modificadas por mim, conforme transvejo cenicamente cada encontro. Porém, não me resta outra saída. "Que alternativa tenho, se não me adapto à maneira habitual de transformar um evento em símbolo, com uma apresentação inevitavelmente mutilada da realidade, traçando um mapa que desenha e recorda algo que não é o território?" (VARLEY, 2010, p. 29).

O próprio mapa é meu alento neste sentido. Ora, como poderia dar conta da vastidão de um território de tão grandes proporções como a Amazônia, contar a história de tantas palhaças atuantes nessa imensidão? Se o mapa não é o território, ao menos dá pistas relevantes para conhecê-lo, embora termine por apresentar uma realidade inventada, como qualquer realidade, após passar pelo corpo da atriz ou da pesquisadora. Desformo a realidade, seguindo a lição do poeta, sem culpa. Assumi, por isso, a cartografia como método de pesquisa e de criação.

Suely Rolnik (2007) acredita que o cartógrafo tenta ser um antropófago-em-nós, devorando todo tipo de matérias, a fim de miscigená-las e, através das misturas, compor seu mapa, constituir sua realidade. Assim vem se constituindo esta cartografia, emprestando e brincando com pedaços de diversas fontes, para formar algo outro. Desse mesmo modo, há de ser constituído o espetáculo em devir, abocanhando encontros e recriando-os em miudezas misturadas.

É como se notasse meu mapa imbuído em um estado de jogo corporal. Para Angel Vianna, jogo corporal é uma improvisação e, ao mesmo tempo, criação (RAMOS, 2007). Os participantes têm a oportunidade de descobrir formas de mover-se, de criar, 
pelos encontros com o outro e com objetos. Uma aprendizagem pela experiência, um fazer ditado pelos próprios participantes envolvidos, cuja maior importância está na relação. "Todo o corpo se volta para perceber o jogo corporal do outro, suas ações e reações" (RAMOS, 2007, p.46), sendo indispensável que ocorra um relacionamento. Através dele, aprimora-se o olhar, a percepção, ou seja, produz-se conhecimento.

Ora, a cartografia, conforme Passos e Barros (2010) e Deleuze e Guattari (1995), não tem objetivos e metas pré-definidas. Ela se constitui no caminho, através dos encontros, nos quais se delineiam por onde seguir e direcionar a atenção do cartógrafo. Um mapa está sempre aberto, reconfigurável, em estado de espontaneidade e improvisação, direcionado pelo confronto entre os meios interno e externo. O mapa e o jogo corporal nascem de encontros, que preenchem espaços e possibilitam a criação.

Falar em improviso a partir da relação, percepção do outro, é, ainda, confundirse com o próprio objetivo do mapa específico a delinear-se nesta pesquisa, pautada, em ritornelo, na transcriação a partir de encontros e no preenchimento do espaço vazio que o estar com outros provoca em mim. A epígrafe deste escrito já trazia a improvisação com o outro como destaque para o substrato de minha escrita. Na verdade, penso que sabia dela desde o momento em que escolhi o objeto da pesquisa. O que vem acontecendo, conforme amadureço, é deixá-lo entranhar-se cada vez mais em minhas pessoalidades, em meu corpo, propondo mesmo que todo o trabalho resulte em uma corporificação da experiência.

Se é que há objeto sobre o qual me debruço em pesquisa, ele segue a lição de Angel Vianna para o objeto a ser utilizado no jogo corporal:

Quando se escolhe um objeto, ele deve ser colocado no maior número de trabalhos de sensibilidade corporal possível: como um todo, sentido nos ossos, nos músculos e na pele. [...]. É um jogo do corpo criativo e comunicador. Não é para competir, e sim para se relacionar, para deixar aflorar toda a percepção corporal dentro do espaço interno, pessoal, parcial e total do sujeito (RAMOS, 2007, p. 52).

Vira um desobjeto, como o pente azul que o menino encontra no quintal, na poesia de Manoel de Barros (2003). Tão entranhado ao chão, ao musgo, de tal maneira incorporado à natureza, o objeto perdera sua "personalidade". Com meu desobjeto de pesquisa ocorre o mesmo: quanto mais jogo com ele, passo a entranhá-lo em mim, e ele deixa de ser objeto e torna-se parte constituinte desta pesquisadora. Sujeito-em-mim.

Seria esta pesquisa e o processo criativo no qual deseja resultar uma espécie de cartografia lúdica, em jogo? Para afirmar isto, precisaria aprofundar-me em aproximações entre jogo e ludicidade, que ainda não dei conta até aqui. De qualquer forma, quando o lúdico me vem em mente, é sobre o jogo que assento meu raciocínio, onde todo o meu corpo torna-se disponível a encontros, entre os meios existentes no sentido de estar viva.

Chego a uma compreensão de algumas pistas por onde seguir com esta pesquisa, explicitamente movida pela necessidade de estar junto. Criar, aqui, é sair da solidão e arriscar-me na permeabilidade de fronteiras pessoais, em dança com alguém. Dança do cômico feminino amazônida. Cabana aberta, deixo entrar outras palhaças, ou vou até elas. Reconfiguro-me. Sempre haverá regras, como no jogo, já que esta é uma pesquisa acadêmica. Elas, no entanto, modificam-se, ampliam-se, reduzem-se, no caminho de configuração do mapa. Da solidão à criação, eu cartografo, jogando, transvendo conceitos, palhaças e Amazônias. 


\section{Referências}

BARROS, Manoel de. Livro sobre nada. Rio de Janeiro: Record, 1996.

BARROS, Manoel de. Memórias inventadas: a infância. São Paulo: Planeta, 2003.

BURNIER, Luís Otávio. A arte de ator: da técnica à representação. 2 ed. Campinas: Editora da Unicamp, 2009.

CAMPOS, Haroldo de. Da transcriação: poética e semiótica da operação tradutora. Belo Horizonte: Viva Voz: FALE/UFMG, 2011.

CASTRO, Alice Viveiros de. O elogio da bobagem: palhaços no Brasil e no mundo. Rio de Janeiro: Família Bastos, 2005.

CASTRO, Felícia de. Palhaças, bem-vindas sois vós!. Pã Revista de Arte e Cultura. 2010. Disponível em: <http://parevista.org/revista/index.php/component/content/article/31-colaboradores/121-felicia-de-castro. html> . Acesso em: 22 jan. 2013.

DELEUZE, Gilles. Diferença e repetição. 2. ed. Rio de Janeiro: Graal, 2006.

DELEUZE, Gilles; GUATTARI, Félix. Acerca do ritornelo. In: Mil Platôs: capitalismo e esquizofrenia. São Paulo: Editora 34, 1997. (Coleção Trans., 4).

FLORES, Andréa Bentes. Olha a palhaça no meio da rua: uma cartografia de Bilazinha da Mamãe pelas feiras livres de Belém. Monografia (Especialização em Estudos Contemporâneos do Corpo). Universidade Federal do Pará, Belém, 2011.

GONÇALVES, Carlos Walter Porto. Amazônia, Amazônias. 3. ed. São Paulo: Contexto, 2012.

GROTOWSKI, Jerzy. Em busca de um teatro pobre. In: FLASZEN, Ludwik; POLLASTRELLI, Carla. O teatro laboratório de Jerzy Grotowski 1959-1969: textos e materiais de Jerzy Grotowski com um escrito de Eugênio Barba; curadoria de Ludwik Flaszen e Carla Pollastrelli com a colaboração de Renata Molinari. São Paulo: Perspectiva: SESC; Pontedera, IT: Fondazione Pontedera Teatro, 2007. p. 105-112.

LECOQ, Jacques. O corpo poético: uma pedagogia da criação teatral. São Paulo: Editora Senac: Edições SESC, 2010.

LÉVI-STRAUSS, Claude. Tristes trópicos. São Paulo: Companhia das Letras, 1996. p. 41-63.

MENEZES, Fernando Chui. Quatro atos de Judite: o corpo feminista da palhaça. Revista Trama Interdisciplinar. São Paulo, v. 2, n. 1, p. 161-168. 2011.

MILLER, Jussara. A escuta do corpo: sistematização da técnica Klauss Vianna. São Paulo: Summus, 2007. 
PASSOS, Eduardo; BARROS, Regina Benevides de. A cartografia como método de pesquisa-intervenção. In: PASSOS, Eduardo; KASTRUP, Virgínia; ESCÓSSIA, Liliana da (Orgs.). Pistas do método da cartografia: Pesquisa-intervenção e produção de subjetividade. Porto Alegre: Sulina, 2010. p. 17-31.

ORLANDI, Luiz B. L. O pensamento e seu devir-criança. Cadernos de Subjetividade. São Paulo, n.12, p. 62-67, 2010.

RAMOS, Enamar. Jogos corporais. In: Angel Vianna: a pedagoga do corpo. São Paulo: Summus, 2007. p. 44-58.

ROLNIK, Suely. Cartografia sentimental: transformações contemporâneas do desejo. Porto Alegre: Sulina: Editora da UFRGS, 2007.

RUSSO, Mary. O grotesco feminino: risco, excesso e modernidade. Rio de Janeiro: Rocco, 2000.

VARLEY, Julia. Pedras d'água: bloco de notas de uma atriz do Odin Teatret. Brasília: Teatro Caleidoscópio, 2010. 